\title{
$\mathrm{CAN}$ 통신을 이용한 모듈전원의 병렬운전에 관한 연구
}

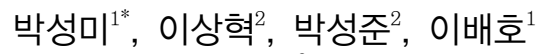 \\ ${ }^{1}$ 전남대학교 컴퓨터공학과, ${ }^{2}$ 전남대학교 전기공학과
}

\section{A Study of Parallel Operation of Module Power using CAN Communication}

\author{
Seong-Mi Park ${ }^{1 *}$, Sang-Hyeok Lee ${ }^{2}$, Sung-Jun Park ${ }^{2}$ and Bae-Ho Lee ${ }^{1}$ \\ ${ }^{1}$ Department of Computer Engineering, Chonnam National University \\ ${ }^{2}$ Department of Electrical Engineering, Chonnam National University
}

\begin{abstract}
요 약 본 논문에서는 $\mathrm{CAN}$ (Controller Area Network) 통신을 이용한 균등한 전류 분배를 위한 새로운 부하분담 (Load-sharing) 알고리즘(Algorithm)을 제안한다. 기존 아날로그 방식과는 달리 디지털 통신을 이용한 강인한 부하분담 특성을 가지며, 모듈마다 독립된 제어기(전압제어기, 전류제어기)가 구성되어 있으며, 마스터(Master)의 지령치 모듈의 지령치에 따라 슬레이브(slave)모듈이 부하분담을 수행한다. 또한 각 모듈 상태를 파악하기 위해 별도의 제어선을 사 용하여 모듈의 고장 상태 및 고장난 모듈의 위치를 정확히 파악함으로써, 효율적이고 고속의 부하분담을 구현하였다. 제작된 병렬 시스템은 각 모듈마다 독립된 제어기가 구성되어 있으며, 본 논문에서는 PSIM을 통한 시뮬레이션과 시 작품 제작을 통해 제안된 알고리즘의 타당성을 검증하였다.
\end{abstract}

\begin{abstract}
In this paper, we proposes new load-sharing algorism for equal current division using CAN communication. Proposed algorithm is different from conventional analog method, it performed strong Load-sharing using bi-direction high speed communication. Each modules constitution on independence controller (voltage controller, electric current controller). In parallel system prototype, each module have controller and performed load-sharing according to master module integral value. Also additional controller use for getting each module situations that fault situation of module and fault locate of module . we implemented high efficient load-sharing and redundancy. In this paper, we verify the validity of proposed algorithm using PSIM program and prototype.
\end{abstract}

Key Words : Parallel Controller, CAN, Load Sharing, Redundancy

\section{1. 서론}

최근 전자 장비 시스템의 첨단화 및 기능의 다양화로 인하여 시스템의 소비 전력이 증가됨에 따라 높은 정격 의 전력용 스위칭 소자를 이용한 단일 대용량 $\mathrm{DC} / \mathrm{DC}$ 컨 버터 대신 복수대의 $\mathrm{DC} / \mathrm{DC}$ 컨버터를 병렬 운전하여 대 전류를 부하에 공급하는 병렬 $\mathrm{DC} / \mathrm{DC}$ 컨버터의 필요성이 크게 대두되고 있다. 이러한 병렬 $\mathrm{DC} / \mathrm{DC}$ 컨버터는 부하 증가 시 용량 증가가 용이해야 하며 시스템의 소형 및 경 량뿐만 아니라 신뢰성 또한 크게 요구되어, 병렬 $\mathrm{DC} / \mathrm{DC}$
컨버터 시스템은 단일 $\mathrm{DC} / \mathrm{DC}$ 컨버터 시스템에 비하여 용량의 대형화는 물론이고 출력의 다양화, 전원의 분산 화, 설계 표준화 및 방열의 용이성 등의 장점을 갖는다. 또한 유지, 보수의 편리함과 확장 가능성에 대한 여유 및 신뢰도 증진을 위한 여분의 전원에 대한 유연성으로 각 모듈은 설계 시 최적의 용량으로 설계됨으로써 비용면에 서 가장 효과적인 설계가 가능하게 된다.

하지만 실질적으로 시스템을 구성하는 소자들의 특성 이 이상적이지 못하고 이에 포함된 기생 성분들이 같지 않기 때문에 모듈간의 임피던스가 서로 다르게 된다. 이 
로 인해 동기가 일치해도 라인 임피던스 및 특성차이로 순환전류가 발생하며 부하가 증가하면 할수록 병렬 시스 템 상호간 심각한 불평형 전류가 흐르게 되어 각 단일 모 듈의 고장 원인이 된다. 뿐만 아니라 이로 인한 시스템의 신뢰성이 현저히 저하되는 심각한 문제점을 가지게 된다. 따라서 이를 제거하기 위한 부하분담과 리던던시 알고리 즘이 필수적이라 할 수 있다[3,6].

기존의 병렬운전의 방식으로는 제어 구조에 따라 병렬 연결된 모듈의 출력전류 정보를 통해 기준 전류를 검출 하여 부하분담을 수행하는 능동전류 분담방식(Active current sharing method)과 출력전압의 강하특성을 이용한 전압강하방식(Voltage droop method)으로 구분된다. 병렬 운전 시 주요 사항으로는 병렬 연결된 모듈의 부하 전류 분배로, 병렬운전 방식 중에 대표적인 제어법으로는 다음 과 같다.

마스터-슬레이브 모듈로 구분되는 마스터 제어법, 출 력전압의 전압강하(Droop)를 이용한 전압강하법, 전류 분 배를 실행하는데 있어 외부 컨트롤러를 사용하는 외부 컨트롤러법, 하나의 공유버스(Share Bus)를 이용한 평균 전류법, 전력편차를 이용한 최대 전류법으로 구분할 수 있다 $[1,5,7]$.

본 논문에서는 기존 아날로그 방식과 달리 디지털 $\mathrm{CAN}$ 통신을 이용하여 보다 효율적이고 강력한 부하분담 기능을 갖는 병렬 제어기를 제안한다. 제안된 구조는 모 듈의 고유 ID에 따라 마스터-슬레이브로 동작하여 독립 병렬형 형태로, 제어선을 이용하여 각 모듈의 상태를 확 인할 수 있다.

실험은 타당성을 검증하기 위하여 PSIM을 이용한 시 뮬레이션을 수행하였고, 실제 $7 \mathrm{kw}$ 급 모듈형 전원장치를 제작하여 효율적인 부하분담과 리던던시가 이루어지는 것을 검증하였다.

\section{2. 기존의 병렬운전 시스템}

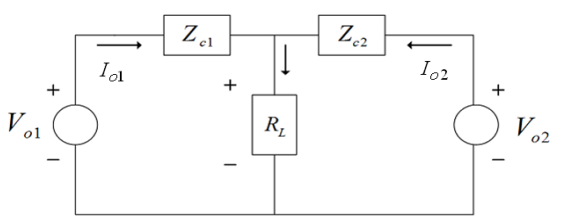

[그림 1] 전력분담 등가회로

[Fig. 1] Power Sharing Equivalent circuit

그림 1 은 병렬 연결된 전원장치의 전력분담 특성을 분 석하기 위한 등가회로이다. $V_{o 1}, V_{o 2}$ 는 각 전원장치의
초기설정 출력전압이며, 출력전압은 각 모듈이 동등한 값 을 가진다. $Z_{c 1}, Z_{c 2}$ 는 각 전원장치 출력단과 부하저항 사이의 선로저항이며, $R_{L}$ 은 부하저항을 나타낸다. 각 전 원장치가 분담하는 출력전류 $I_{o 1}, I_{O 2}$ 는 식 (1), (2)와 같다.

$$
\begin{aligned}
& I_{o 1}=\frac{\left(V_{o 1}-V_{o 2}\right) \cdot R_{L}+V_{o 2} \cdot Z_{c 1}}{R_{X}} \\
& I_{o 2}=\frac{\left(V_{o 2}-V_{o 1}\right) \cdot R_{L}+V_{o 1} \cdot Z_{c 2}}{R_{X}}
\end{aligned}
$$

이때 $R_{X}$ 는 식 (3)과 같다.

$$
R_{X}=\left(Z_{c 1}+Z_{c 2}\right) \cdot R_{L}+Z_{c 1} \cdot Z_{c 2}
$$

병렬 연결된 모듈이 동등한 전류를 분담하고 있다면 $I_{o 1}=I_{o 2}$ 이므로 식 (1)과 식 (2)로부터 다음의 식(4)를 얻 을 수 있다.

$$
V_{o 2} \cdot Z_{c 1}-V_{o 1} \cdot Z_{c 2}=2 \cdot R_{L} \cdot\left(V_{o 2}-V_{o 1}\right)
$$

식 (4)에서 각 모듈의 초기설정 출력전압이 같다고 가 정하면 $Z_{c 1}=Z_{c 2}$ 가 되어야 한다. 그러나 $Z_{c 1}$ 과 $Z_{c 2}$ 는 일치하지 않으므로, 균등한 출력전류를 분담하기 위해서 는 초기설정 출력전압 $V_{o 1}, V_{o 2}$ 를 제어하여야 함을 알 수 있다[2,5].

\section{1 전압강하 방식}

전압강하 방식은 출력전압의 강하특성에 의존하여 부 하분담을 제어하며 분담하는 부하 전류에 비례하여 출력 전압을 강하시키는 방식으로 병렬 연결된 전원장치 사이 에 전류 정보 교환선을 사용하지 않고 각 모듈이 독립적 으로 부하 분담을 제어하게 된다. 이 방식은 낮은 전류 분배에서 좋지 않은 전류 분배를 보이며 부하 레귤레이 션의 저하, 다른 전력 등급을 가진 병렬 모듈 사이에서의 전류 분해를 하는데 있어 어려움이 있다.

\section{2 전용마스터방식}

전류 모드 전원장치는 부하 전류분배 형태를 이루기 위해서는 여러 가지 상황을 수용할 수 있다. 한 가지 방 법은 전압 제어를 하기 위해서 마스터(Master)모듈을 선 택하고, 남아 있는 모듈(slaves)은 전류 모드로서 동작하 
도록 한다. 이 방법은 전압 오차(Error Voltage)가 부하 전 류에 비례하므로 전류 모드 제어로 용이하다. 이 기술은 부하 전류분배를 이룰 수 있지만, 리던던시를 이룰 수 없 다. 왜냐하면, 마스터가 고장이 나면, 전 시스템이 사용되 어 질 수 없기 때문이다. 이 기술의 또 다른 단점은 높은 대역폭(High bandwidth) 전압 루프가 시스템 주위에서 실 리며, 노이즈(noise)가 생기기 쉽다는 점이다[1].

\section{3. 제안된 병렬운전 시스템}

\subsection{CAN 통신}

\subsubsection{CAN 특징}

$\mathrm{CAN}$ 통신은 독일의 Robert Bosch사에서 자동차 산업 분야에 적용되기 위해 고안된 시리얼 통신 방법이다. 2 가 닥 꼬임선(Twist pair wire) 반이중 통신 방식으로 고속 응용 시스템에 적합하며, 주요 특징으로는 다음과 같다 [3].

i ) 다중통신(멀티-마스터 / 멀티-슬레이브)

ii) 시리얼 버스 타입

iii) 메시지 기반

iv) 멀티마스터 구조로 데이터충돌 발생문제 해결: CSMA/CD+AMP (Carrier Sense Multiple Access and Collision Detection with Collision Resolution)

\subsubsection{CAN 동작}

$\mathrm{CAN}$ 통신의 동작 원리는 그림 2 와 같다.

i ) $\mathrm{CAN}$ 노드에 메시지를 보내기 전에 $\mathrm{CAN}$ 버스 라 인이 사용 여부 파악

ii) 메시지 간 충돌 검출 수행 (이더넷 통신 방법과 유 사)

iii) 데이터 메시지는 주소가 아닌 식별자 (11bit or 29bit ID)로 구분

iv) 메시지를 수신하여 식별자를 통해 사용여부 결정

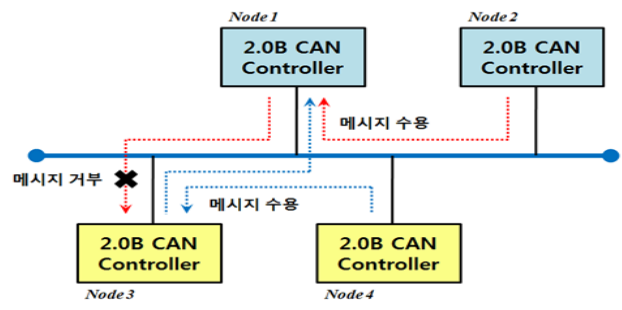

[그림 2] CAN 데이터 수신 방식

[Fig. 2] Receiver method of Can data

\subsubsection{CAN 통신회로}

기존의 아날로그 방식과 달리 고속 통신과 디지털 제 어를 수행하고 실시간 제어를 위한 시분할 토큰버스 방 식을 적용함으로서 효율적인 부하분담 및 리던던시를 구 현하는데 RS - 485 통신을 이용한 병렬 운전제어 구현과 리던던시를 이용하여 모듈의 사고 시 효과적으로 부하분 담이 유지된다. 다만 데이터 충돌 방지를 위한 대책이 필 요하다[3].

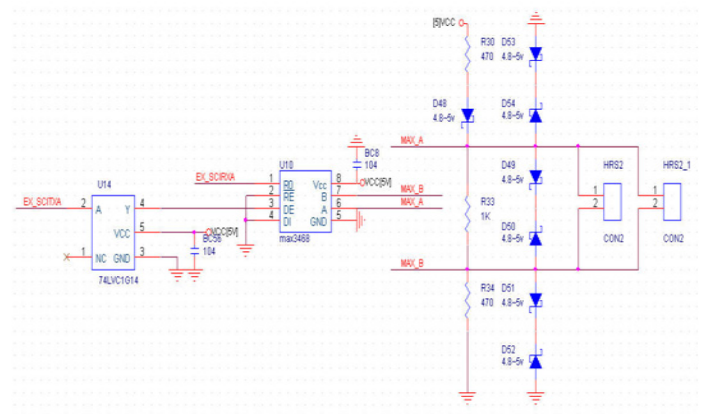

[그림 3] Data 충돌보호 회로도

[Fig. 3] Data collision protection circuit

그림 3은 RS-485통신에 데이터 충돌보호 회로를 추가 한 회로 구성도이다. CAN통신은 자체적으로 데이터 충 돌방지 회로를 구성하고 있어 본 논문에서는 $\mathrm{CAN}$ 통신 을 적용하였다.

\section{2 와치독(Watch-Dog)}

와치독 기능은 시스템의 높은 안정성과 신뢰성을 향상 시키는 기술로서, 본 논문에서는 통신 기반의 병렬운전에 적합한 와치독 회로를 그림 4 와 같이 설계하였다.

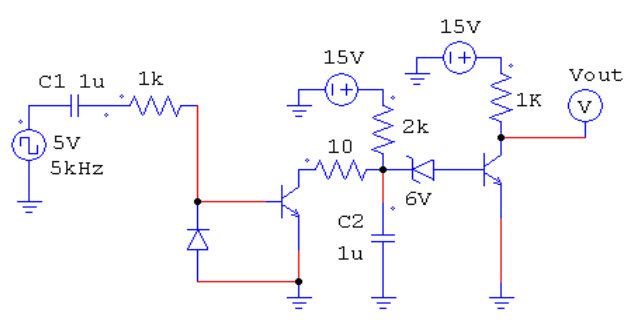

[그림 4] 와치독 회로

[Fig. 4] WatchDog Circuit

와치독 회로는 $\mathrm{CAN}$ 통신 인터럽트에 의해 발생되는 펄스를 입력 받아 High 신호가 출력된다. 만약 CPU 오동 작으로 펄스가 미발생 할 경우에는 와치독 1 의 경우 Low 신호가 출력되어 마스터에게 모듈의 고장을 알리게 되고, 
와치독 2의 경우는 Signal Relay를 사용하여 라인을 분리 한다.

\subsection{1 구성도}

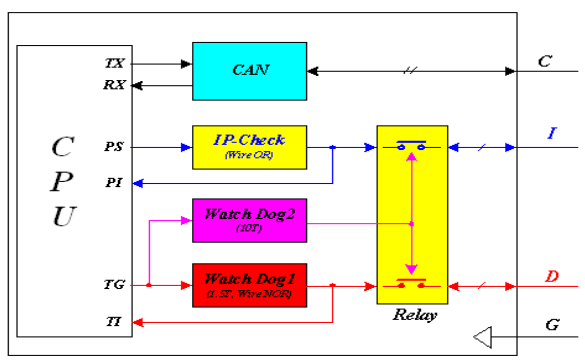

[그림 5] 모듈 구조

[Fig. 5] Configuration of Module

병렬제어기에 대한 모듈 구성도는 그림 5 와 같이 [C] 는 통신선, [I]는 Fault 모듈의 ID를 체크하는 제어선, [D] 는 동작 모듈의 Fault를 체크하는 제어선, [G]는 그라운드 선을 의미한다. 제어선 [I]는 Emitter Follow로 구성되어 OR 통신을 이루게 된다. 즉, 각 모듈의 출력 파형을 Sum 하여 마스터에서 Fault 모듈의 ID를 확인한다. 제어선 [D]는 Open collector로 구성되어 NOR 통신을 이루게 된 다. 즉, 모듈 중에 Fault 발생시, 제어선 파형이 Low가 되 어 마스터에서 Fault 모듈의 여부를 확인한다.

본 구성도는 $\mathrm{CAN}$ 통신과 디지털 입출력포트를 결합한 새로운 통신 시스템으로 마스터에서 발생하는 부하분담 을 위한 각종 지령치는 $\mathrm{CAN}$ 통신을 통하여 슬레이브에 각 모듈을 전달하고, 슬레이브의 고장여부는 Wire-OR로 연결된 디지털 입출력비트로 마스터에 전달하는 구조로 되어 있다. 또한 슬레이브 고장 시 디지털 선의 점유를 방지하기 위해 고장난 모듈을 통신선과 물리적으로 분리 하기 위한 릴레이로 구성되어 있다. 슬레이브 고장은 본 연구에서 특별히 제작한 와치독으로 제어된다.

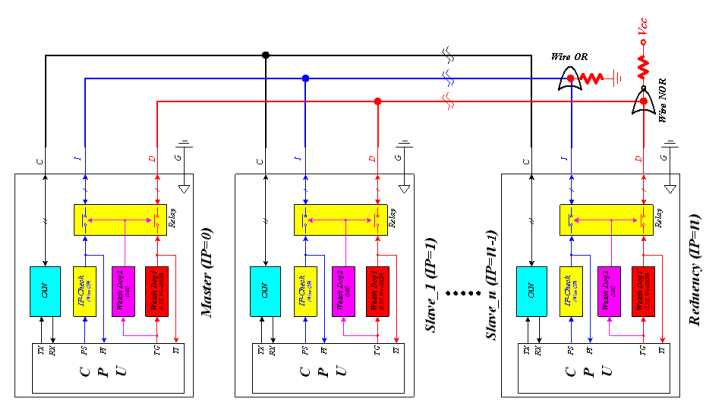

[그림 6] 시스템 구성도

[Fig. 6] System Block Diagram
그림 6은 전체 시스템 구성도로 제어선의 동작에 따라 외부에 OR 또는 NOR 회로를 구성함으로써, 마스터 모 듈이 다른 모듈 상태 및 Fault 모듈을 파악할 수 있다.

$\mathrm{RS}-485$ 에서와 같이 CAN통신에서 다수의 슬레이브가 있는 경우 양방향 통신으로 마스터가 각 모듈의 동작여 부만을 확인하는데 부하가 크게 작용하는 단점이 있다. 따라서 CAN통신과 병렬로 Wire AND로 구성된 신호선 이 존재한다면 단순히 각 IP모듈의 고장여부의 정보인 2 진 비트 정보를 취하는데 CAN통신방식의 시간적 제약성 을 극복할 수가 있다. 이 방식을 사용하면 CAN은 단순히 MASTER에서 Slave측으로 Data를 전달하고 슬레이브측 의 정보는 Digital로 점검이 가능하다.

\subsection{2 제어기}

기존의 부하분담과 리던던시 제어기는 마스터에서만 전압제어를 행하고 슬레이브 측에서는 마스터가 발생한 전류제어를 행하게 된다. 이 경우 마스터의 고장으로 예 비마스터가 마스터가 되는 경우 현재 마스터 전압제어기 의 상태변수 값에 대한 정보가 유실되어 기동과 같은 조 건에서 마스터 권한을 이양받기 때문에 리던던시 시 출 전전압의 큰 변동은 필수적이다.

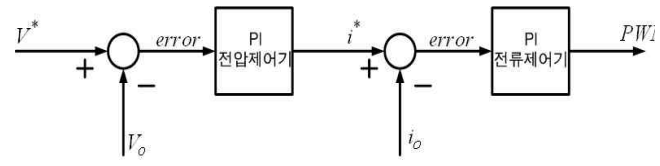

[그림 7] 모듈 제어 블록도

[Fig. 7] Module Block Diagram

그림 7은 부하분담과 리던던시를 위해 본 논문에서 제 안한 방식으로 기존구조와 차이점은 모든 모듈에서 전압 제어기 수행은 행하며 각 전압제어기의 편차는 마스터의 상태변수인 적분값을 공유함으로써 제거하였다. 이 경우 마스터의 고장으로 예비마스터가 마스터가 되는 경우 현 재 마스터 전압제어기의 상태변수 값에 대한 정보와 같 이 마스터 권한을 이양받기 때문에 리던던시 시 출전전 압 변동을 최소화 할 수 있는 구조가 된다. 전류제어기는 기존방식과 동일하다. 이로 인해 마스터 모듈의 고장 시 예비 마스터로 교체 되는 과정에서 빠른 속응성을 가지 고 부하분담 및 고응답의 리던던시를 이룰 수 있다.

\section{3 부하분담}

본 연구에서는 $\mathrm{n}+1$ 개의 모듈이 존재할 때 $\mathrm{eCAN}$ 통신 을 이용하여 각 모듈의 상태를 판단하고 효과적으로 부 하분담이 이루어질 수 있도록 하는 리던던시 알고리즘을 채택하였다. 


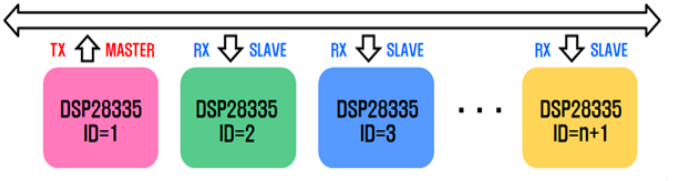

[그림 8] CAN통신 부하분담

[Fig. 8] CAN communication Load-Sharing

이의 구조 및 동작 상태는 그림 8 과 같이 여러 대의 모 듈이 존재할 때 1 개의 마스터와 여러 개의 슬레이브 모듈 로써 역할을 분담하게 된다. 마스터 모듈의 경우 각 슬레 이브 모듈로 전류 지령치를 비롯하여 동작 유무 상태를 체크하고 관리하게 된다.

\section{4 리던던시}

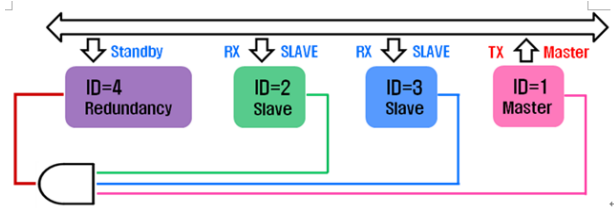

[그림 9] CAN통신 리던던시

[Fig. 9] CAN communication Redundancy

그림 9에서 추가적인 통신선을 사용하여 항상 대기해 있던 모듈 하나가 1 개 이상의 모듈이 고장 났을 시 바로 투입되어 리던던시를 나타내고 있다.

마스터 모듈을 포함해 모든 모듈의 상태를 리던던시 모듈이 판단하고 있으면서 일정 모듈이 고장 났을 경우 바로 투입될 수 있게 Standby 하고 있는 것을 나타낸다. 이렇게 Standby 모듈을 구성하고 각 모듈의 고장 상태를 판단함으로써 효과적인 리던던시를 이루는 방식을 채택 하였다.

\section{4. 시뮬레이션}

본 논문에서는 병렬통신과 제안하는 제어기에 의한 부 하분담이 이루어지는 것을 검증하기 위해 PSIM을 통한 시뮬레이션을 수행하였다. 자동 ID설정 알고리즘은 하드 웨어적인 부분의 영향을 받기 때문에 시뮬레이션에서는 $\mathrm{ID}$ 를 모듈에 직접 입력하였다. 고유 $\mathrm{ID}$ 에 의해 4 개의 전 원모듈은 각각 $1 \sim 4$ 번의 고유 $\mathrm{ID}$ 를 지정받게 되고 $\mathrm{ID}$ 가 가장 높은 모듈은 리던던시 모듈로 설정되어 예비전원으 로 대기한다. 부여받은 $\mathrm{ID}=1 \sim 3$ 모듈은 부하분담을 이루 며 전류를 분담하게 되고, 이때 시뮬레이션 에서는 $\mathrm{ID}=3$
이 마스터가 되며 $\mathrm{ID}=1$ 과 $\mathrm{ID}=2$ 는 슬레이브로 동작하게 된다. 파형에서 보이는 바와 같이 전원투입 시 자신의 ID 를 확인하여 3 대의 모듈이 부하분담을 이루고 있음을 알 수 있다.

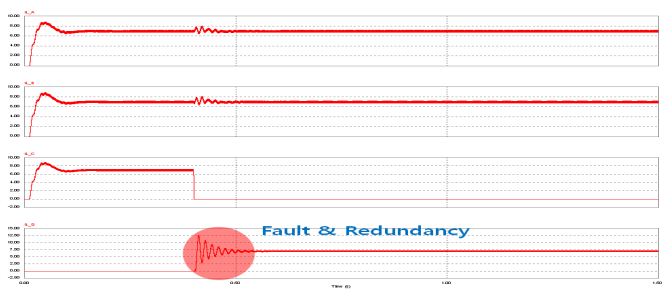

(a) 제어기 적용하지 않았을 때 파형

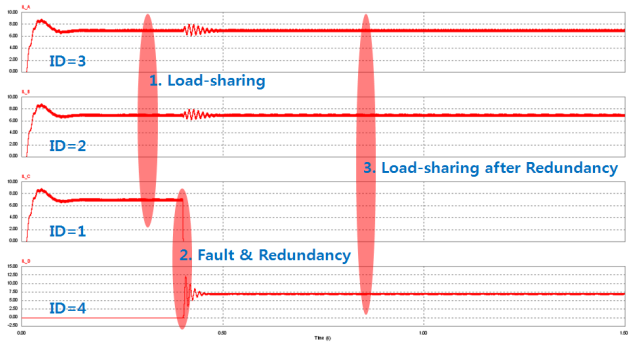

(b) 제어기 적용했을 때 파형

[그림 10] 시뮬레이션 파형

[Fig. 10] WaveForm of simulation

마스터 모듈에 사고(Fault)가 발생 하였을 시 대기하고 있던 $\mathrm{ID}=4$ 는 리던던시 기능으로 사고와 동시에 투입되는 데, 그림 10 에서와 같이 제어기 미적용 시 과도기가 제 어기 적용시보다 오래 지속되는 것을 확인 할 수 있다.

\section{5. 실험 및 결론}

제안하는 디지털 병렬통신을 이용한 부하분담 알고리 즘에 의한 전원장치의 타당성을 시뮬레이션을 통해 검증 하였고, TI사의 TMS320F28335 와 Transceiver (SN65HVD231)를 사용하여 구현하였다.

그림 11은 통신 출력 파형으로 (a) 동기신호에 의한 인 터럽트 (b) 파형은 통신 인터럽트에 의한 펄스 파형과 Emitter Follow로 구성된 OR 통신 파형이다. (c) 파형은 마스터 모듈 Fault시, 리던던시 기능으로 600us 후에 통 신이 이루어짐을 확인할 수 있다. 제안한 병렬 시스템은 각 모듈마다 독립된 제어기가 구성되어 있으며, 마스터 모듈의 지령치에 따라 슬레이브 모듈이 부하분담을 수행 한다. 제어선을 사용하여 모듈의 고장 상태 및 고장난 모 
듈의 위치를 정확히 파악함으로써, 효율적이고 고속의 부 하분담이 가능하다. 모듈 전원 제어 기술 개발을 통하여 고성능의 단일 용량 DC 모듈과 가격 경쟁력 확보로 산업 용 $\mathrm{DC}$ 전원시장을 확대 가능할 것으로 판단된다.

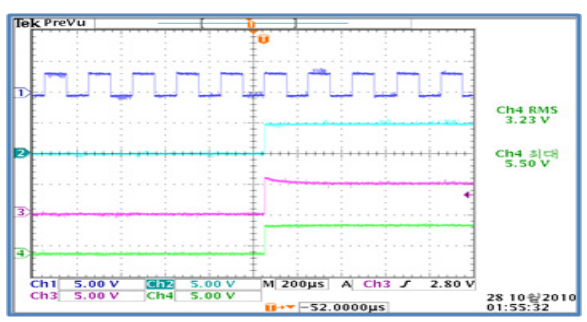

(a)

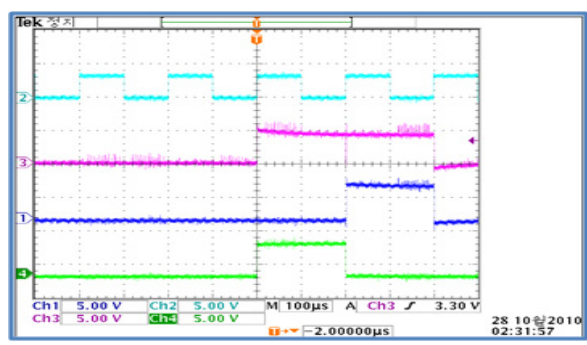

(b)

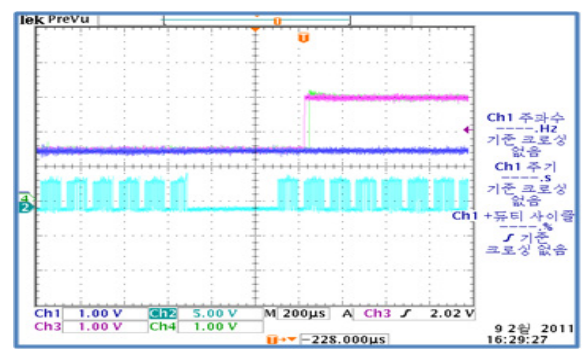

(c)

[그림 11] CAN통신 파형

[Fig. 11] WaveForm of CAN Communication

\section{References}

[1] Jung Won Kim, Hang Seok Choi, Cho, B.H., "A Novel Droop Method for Converter Parallel Operation" APEC 2001, pp.959-964, 2001.

[2] Hong-Ju Ju, Sang-Hyuk Lee, Seung-Ryong Kim, Kang-Soon Ahn, Sung-Jun Park, "A Novel Parallel Communication Algorithm and Load Sharing Electronic Load", The transactions of the korean institute of power electronics, Vol. 2010 No.7

[3] Seong Mi Park, Chun-Sung Kim, Sang - Hyeok Lee,
Sang Hun Lee, Sung-Jun Park, Bae Ho Lee, "Load-Sharing Algorithm Using Digital Parallel Communication", The transactions of the korean institute of power electronics, Vol. 16, No.1, pp. 50 57.

[4] Keon Young Yi, "An Implementation of The Position Controller for Multiple Motors Using CAN", The transactions of the Korean Institute of Electrical Engineers, Vol.51 No.2, 2002.

[5] 손호섭, "Study of parallel operation of DC power supplies for equal load sharing",Master's thesis, Pusan university electric engineering, 2003

[6] Shiguo Luo, Zhihong Ye, Ray-Lee Lin and F. C. Lee, "A classification and evaluation of paralleling methods for power supply modules", IEEE Power Electronics Spec. Conf, pp.901-908, 1999.

[7] Wu, R-H, Kohama, T., kodera, Y., Ninomiya, T., Ihara, F., "Load-current-sharing control parallel operation of DC-to-DC converters", PSEC '93 pp.101-107.1993.

\section{박 성 미(Seong-Mi Park)}

[정회원]

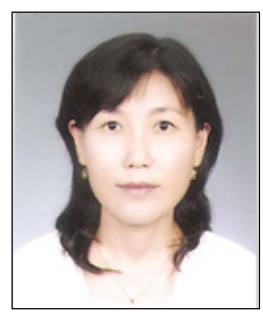

- 1986년 2월 : 전남대 계산통계학 과졸업

- 2001년 2월 : 전남대 컴퓨터공학 과졸업(석사)

- 2011년 8월 : 전남대 컴퓨터공학 과 졸업(박사)

<관심분야>

통신, SMPS

\section{박 성 준(Sung-Jun Park)}

[정회원]

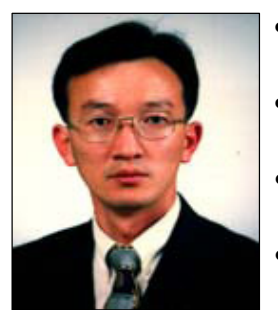

- 1991년 2월 : 부산대 전기공학과 졸업

- 1993년 2월 : 동 대학원 전기공 학과 졸업(석사)

- 1996년 2월 : 동 대학원 전기공 학과 졸업(박사)

- 2002년 2월 : 동 대학원 지능 기계공학과 졸업(공박)

- 2003년 8월 현재 : 전남대학교 전기공학과 부교수

<관심분야>

태양광, 풍력발전 
이 상 혁(Sang-Hyeok Lee)

[정회원]

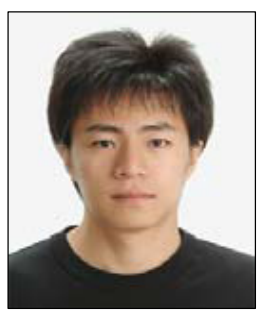

- 2007년 2월 : 한밭대 제어계측공 학과 졸업

- 2009년 2월 : 동 대학원 제어계 측공학과 졸업(석사)

- 2009년 3월 현재 : 전남대 전 기공학과 박사과정

<관심분야>

신재생에너지, 인버터

이 배 호(Bae-Ho Lee)

[정회원]

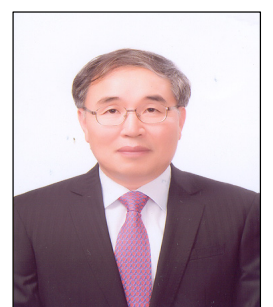

- 1978년 2월 : 한양대 전자공학과 졸업

- 1980년 2월 : 한국과학기술원 (KAIST) 전기 및 전자공학과 졸 업(석사)

- 1993년 2월 : University of Missouri, 전기 및 컴퓨터공학과 졸업(박사)

- 1993년 2월 현재 : 전남대학교 공과대학 전자컴퓨터 공학부 교수

<관심분야>

통신, 컴퓨터비젼 